\title{
Behavior of Solid Electrolyte in Li-Polymer Battery with NMC Cathode via in-situ Scanning Electron Microscopy
}

Shirin Kaboli ${ }^{1}$, Hendrix Demers ${ }^{1}$, Andrea Paolella ${ }^{1}$, Ali Darwiche ${ }^{1}$, Martin Dontigny ${ }^{1}$,

Daniel Clément ${ }^{1}$, Abdelbast Guerfi ${ }^{1}$, Michel L. Trudeau ${ }^{1}$, John B. Goodenough ${ }^{2}$ and Karim Zaghib*1 $^{2}$

${ }^{1}$ Hydro-Québec's Center of Excellence in Transportation Electrification and Energy Storage, Varennes, Québec J3X 1S1, Canada

${ }^{2}$ University of Texas at Austin, 202 Spence St, College Station, TX 77840, United States

Keywords: In-situ, all-solid batteries, polymer degradation, NMC cathode, degassing, dendrites

*Corresponding Author: zaghib.karim@hydro.qc.ca 

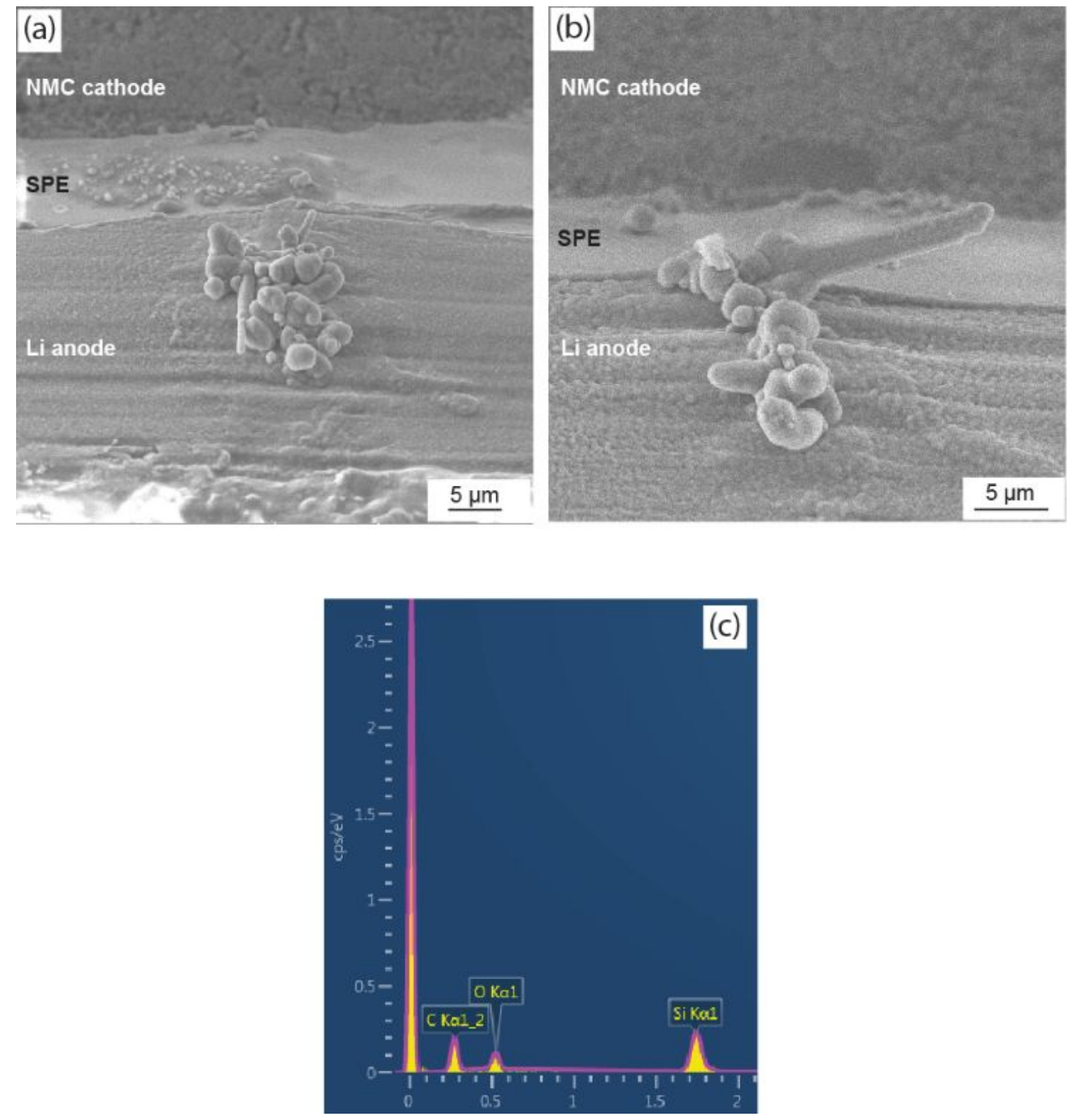

Figure S1. (a) and (b) More examples of dendrites forming in the Li anode during cycling with (c) the corresponding energy dispersive spectroscopy (EDS) analysis showing Li, C and $\mathrm{O}$. The Si peak is due to the resin in the sample assembly. 


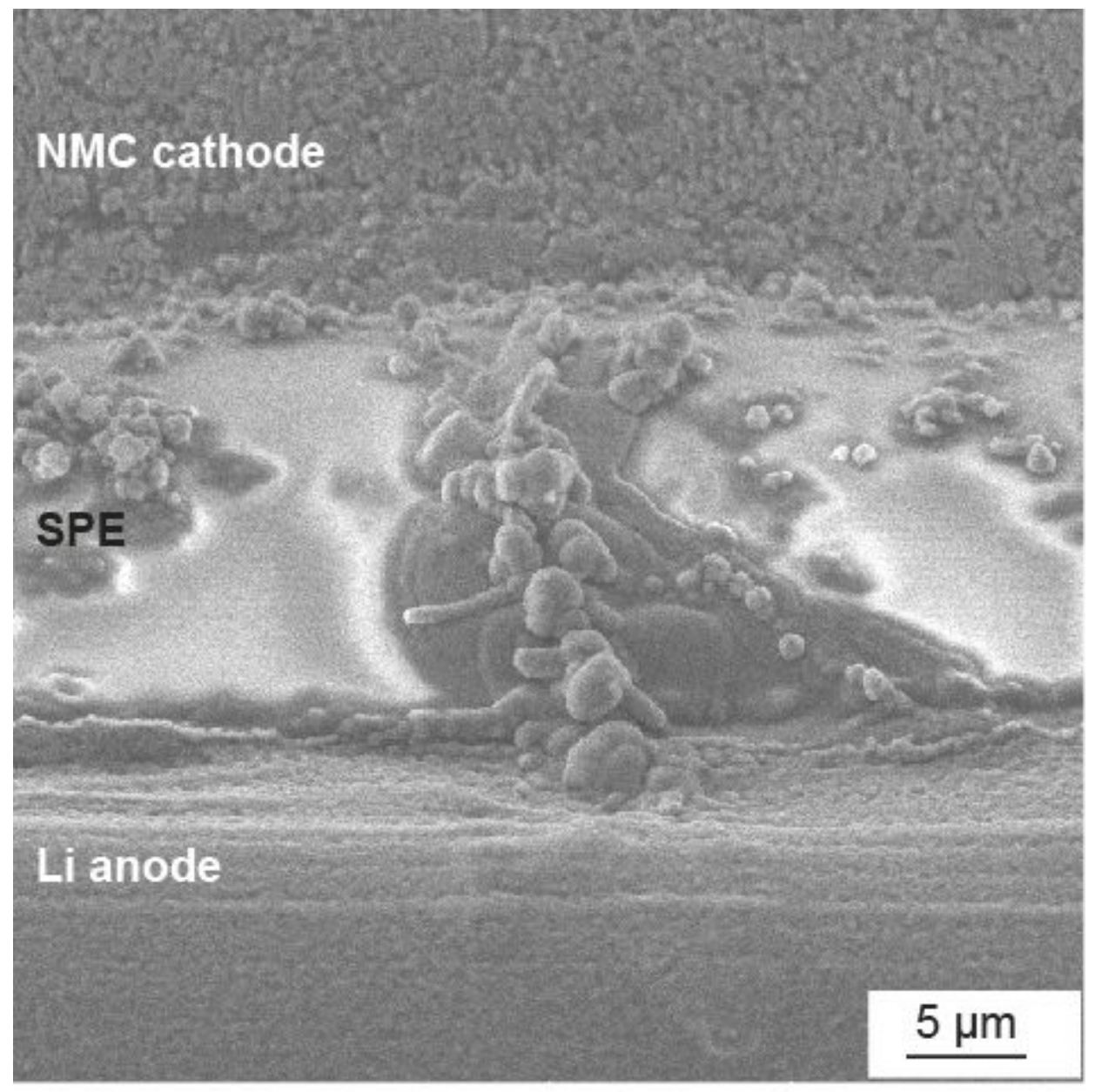

Figure S2. The path of Li dendrites connecting Li anode to the NMC cathode, leading to a short circuit of the cell. 

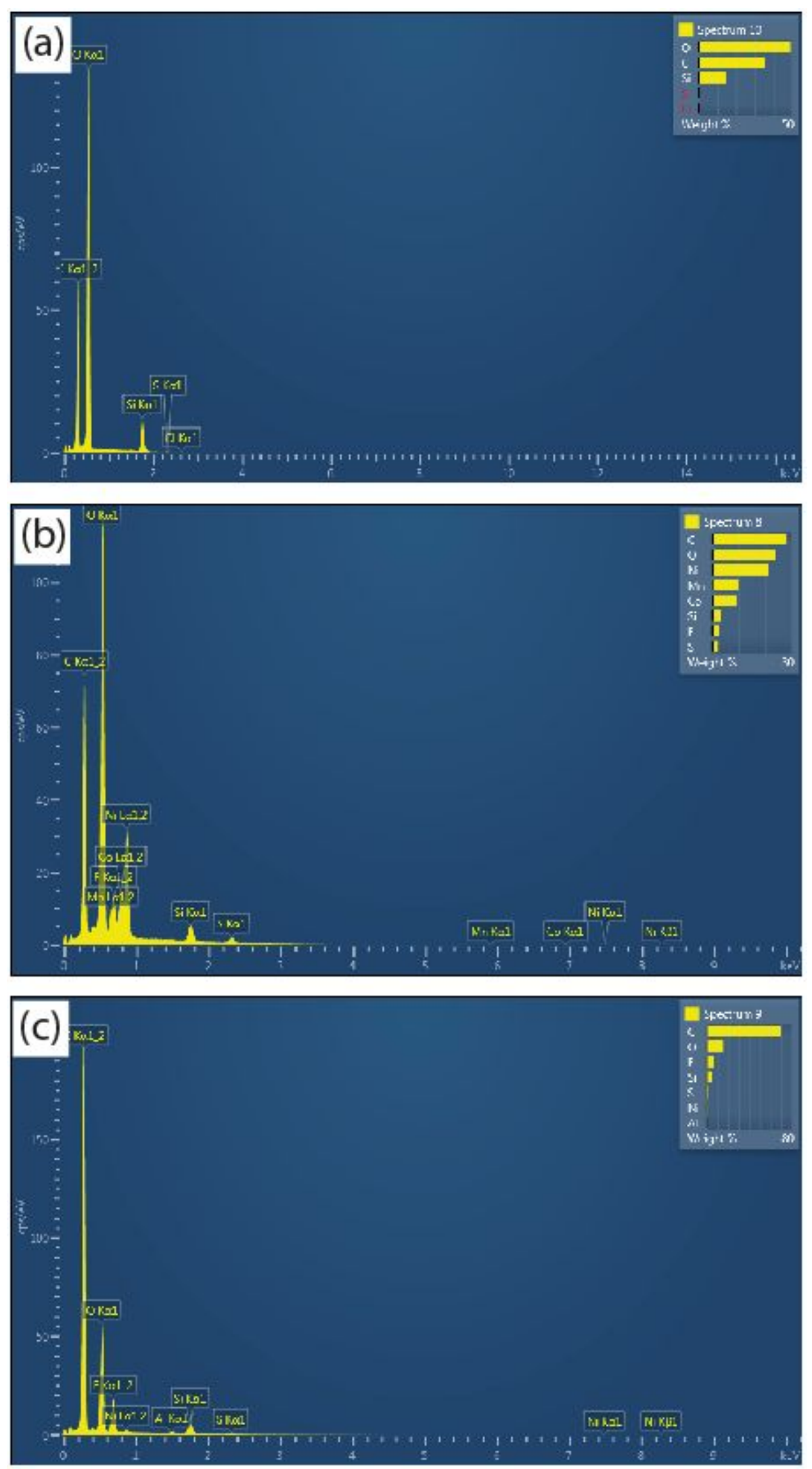

Figure S3. The energy dispersive spectroscopy (EDS) analysis of cell components after cycling from (a) Li anode, (b) SPE and (c) NMC cathode. 


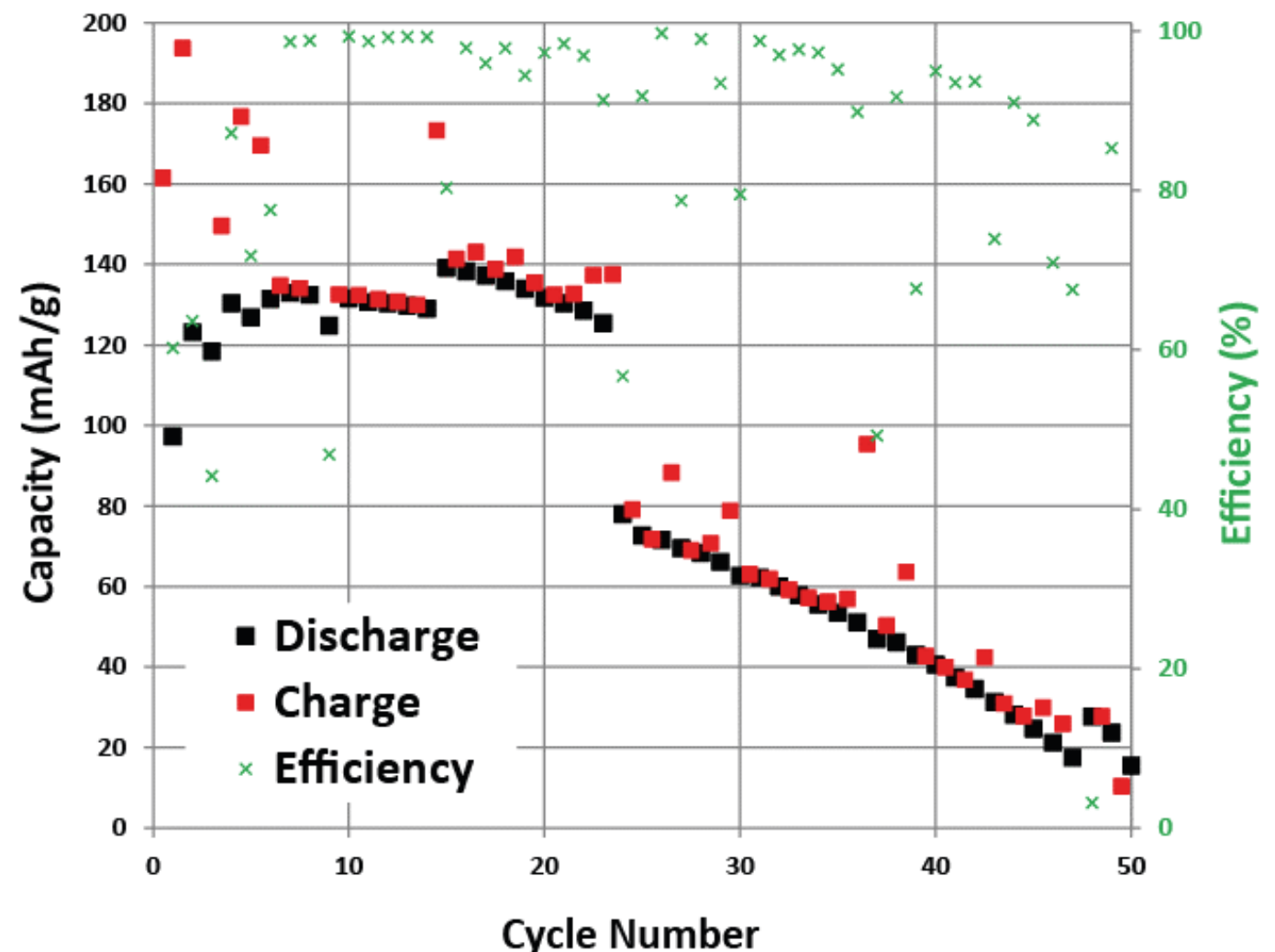

Figure S4. Plot of capacity and efficiency as a function of cycle number for the in-situ test shown in Figure 2a in the manuscript. 